\title{
Uncoupling Protein 2 Regulates Palmitic Acid-Induced Hepatoma Cell Autophagy
}

\author{
Jiaxin Lou, Yunjiao Wang, Xuejiang Wang, and Ying Jiang \\ Department of Pathophysiology, Capital Medical University, 10 You An Men Wai Xi Tou Tiao, Beijing 100069, China \\ Correspondence should be addressed to Ying Jiang; jiangying278@126.com
}

Received 10 April 2014; Revised 29 June 2014; Accepted 30 June 2014; Published 4 August 2014

Academic Editor: Patrice Codogno

Copyright ( 2014 Jiaxin Lou et al. This is an open access article distributed under the Creative Commons Attribution License, which permits unrestricted use, distribution, and reproduction in any medium, provided the original work is properly cited.

\begin{abstract}
Mitochondrial uncoupling protein 2 (UCP2) is suggested to have a role in the development of nonalcoholic steatohepatitis (NASH). However, the mechanism remains unclear. Autophagy is an important mediator of many pathological responses. This study aims to investigate the relationship between UCP2 and hepatoma cells autophagy in palmitic acid- (PA-) induced lipotoxicity. H4IIE cells were treated with palmitic acid (PA), and cell autophagy and apoptosis were examined. UCP2 expression, in association with LC3-II and caspase-3, which are indicators of cell autophagy and apoptosis, respectively,was measured. Results demonstrated that UCP2 was associated with autophagy during PA-induced hepatic carcinoma cells injury. Tests on reactive oxygen species (ROS) showed that UCP2 overexpression strongly decreases PA-induced ROS production and apoptosis. Conversely, UCP2 inhibition by genipin or UCP2 mRNA silencing enhances PA-induced ROS production and apoptosis. Autophagy partially participates in this progress. Moreover, UCP2 was associated with ATP synthesis during PA-induced autophagy. In conclusion, increasing UCP2 expression in hepatoma cells may contribute to cell autophagy and antiapoptotic as result of fatty acid injury. Our results may bring new insights for potential NASH therapies.
\end{abstract}

\section{Introduction}

The uncoupling proteins (UCPs) belong to the mitochondrial anion transporter superfamily in the inner mitochondrial membrane $[1,2]$, and UCP2 is believed to play a role in adaptive thermogenesis and lipid metabolism [3]. Moreover, the promoter region of UCP2 contains Sp1, double E-box, and sterol response elements, which could explain why UCP2 is upregulated in response to high levels of fatty acids, obesity, fasting, leptin, and other conditions [4,5]. Although normal healthy hepatocytes do not express UCP2, there is an increase in expression of this protein following oxidative stress and steatosis [6]. It has been suggested that UCP2 has a role in the development of nonalcoholic fatty liver disease (NAFLD). However, the mechanism remains unclear. UCP2 has been reported to play a role in antioxidant defense [7], as inhibition with the specific inhibitor genipin or inhibition by UCP2 siRNA increases mitochondrial ROS levels, while overexpression of UCP2 diminishes ROS production [8]. These findings suggest that UCP2 might influence the development of NAFLD by regulating ROS production.
Nonalcoholic fatty liver disease (NAFLD) is the most common form of chronic fatty liver disease in Western countries. NAFLD refers to a wide spectrum of liver damage from steatosis to nonalcoholic steatohepatitis (NASH) and, lastly, cirrhosis. NASH is known to be a significant cause of cryptogenic cirrhosis, and therefore it has attracted more attention in the past few years. Studies have shown that FFAs-induced lipotoxicity has been documented to play an essential role in the pathogenesis of NASH [9], and our latest study has shown that palmitic acid- (PA-) induced apoptosis plays an important role in the pathogenesis and development of NASH [10]. At present there is accumulating evidence suggesting that autophagy is involved in the physiological and pathological responses of cells to lipid stimulation $[4,5]$. With the evidence that autophagy could regulate hepatic lipid stores [11], and with loss of autophagic function, white adipocyte differentiation was blocked in vitro and white adipose tissue mass was markedly decreased in vivo. Decreased lipid storage occurred with these changes, and this effect along with an increase in the mass of normal brown adipose 
tissue led to a significantly increased rate of fatty acid $\beta$ oxidation [12]. A previous study has shown that PA also triggers autophagy responses following hepatic lipotoxicity [13], which implies that autophagy may be involved in the etiology of NASH.

Autophagy is a lysosome-mediated degradation process for nonessential or damaged cellular constituents. It has a multistep process, including the formation of doublemembrane vesicles known as autophagosomes [14]. Moreover, autophagy has been shown to have a critical role in the regulation of hepatocellular lipid accumulation and liver injury during oxidative stress [15]. In vivo studies have indicated that starvation-stimulated macroautophagy provides the liver with a lipid challenge in the form of increased serum FFAs and that the autophagic pathway selectively targets lipids for breakdown in response to this physiological stimulus [11]. Moreover, UCP2 has been shown to trigger ROS-dependent autophagic cell death in pancreatic adenocarcinoma cells [16]. These studies prove that UCP2 probably mediates FFA-induced hepatocyte autophagy.

Although the mechanism of how did UCP2 mediate PA-induced autophagy in hepatocytes remains unclear, insights into these mechanisms may be useful in designing effective management strategies in dealing with NASH. Therefore, in the present study, we tested the autophagic responses and the underlying mechanisms following PAinduced injury. We observed the induction of autophagy by PA and UCP2 overexpression decreased ROS production. Moreover, UCP2 could enhance hepatoma autophagy, such that UCP2-mediated autophagy induced by PA was first found to serve as an antiapoptotic mechanism to oppose the lipotoxic effects. These results indicate that modulation of UCP2 can serve as a potential experimental therapy for NASH caused by the lipotoxic effects of PA.

\section{Materials and Methods}

2.1. Cell Culture and PA Treatment. H4IIE cells, a rat hepatoma cell line, were cultured in Dulbecco's modified Eagle's medium (DMEM; Invitrogen) with $10 \%$ (v/v) fetal bovine serum (Hyclone, Rockford, IL, USA), penicillin (100 UI/mL), and streptomycin $(100 \mathrm{UI} / \mathrm{mL})$. All cell cultures were maintained in a $37^{\circ} \mathrm{C}$ incubator with $5 \%(\mathrm{v} / \mathrm{v}) \mathrm{CO}_{2}$. To induce cellular damage, $250 \mu \mathrm{M}$ PA (Sigma, St. Louis, MO, USA) was added to serum-free DMEM medium after the cells grew to $\sim 70-80 \%$ confluence. PA-BSA (bovine serum albumin) conjugate was prepared as described previously [17]. In brief, a $100 \mathrm{mM}$ solution of $\mathrm{PA}$ in $0.1 \mathrm{M} \mathrm{NaOH}$ was incubated at $80^{\circ} \mathrm{C}$, and fatty acid soaps were then complexed with $10 \%$ $(\mathrm{w} / \mathrm{v})$ BSA in phosphate buffered saline (PBS) at a 3.5:1 molar ratio of PA to fatty acid free BSA (Wako, Japan). The BSA was used as a vehicle control. CQ (Sigma, USA) was used to block lysosomal function, and the later degradation stage of autophagy was used to measure autophagic flux in cells.

2.2. Electron Microscopy. H4IIE cells were seeded on $100 \mathrm{~mm}$ plates at a density of $10^{6}$ cells/plate. After the respective treatments for $6 \mathrm{~h}$, cells were fixed with $3 \%(\mathrm{v} / \mathrm{v})$ glutaraldehyde and washed three times with $0.1 \mathrm{M}$ phosphate buffer $(\mathrm{pH}$ 7.4). Cells were postfixed with $1 \%(\mathrm{v} / \mathrm{v}$ ) osmic acid followed by dehydration with an ascending series of alcohol before being embedded in araldite for $24 \mathrm{~h}$. After dehydration, thin sections were cut and stained with uranyl acetate and lead citrate. Digital images were obtained using a JEM 1016CX electron microscope. Random images were obtained.

2.3. Cell Proliferation Assay. Cells were seeded in 96-well plates $\left(10^{5}\right.$ cells/well). After $24 \mathrm{~h}$, cells were treated with various compounds and further incubated for the indicated times (see legends to Figure 1(a)). At the end of the treatments, cells were stained with the cell proliferation reagent WST1 (Roche, Germany). The dye was solubilized in serum-free DMEM medium and measured photometrically at $450 \mathrm{~nm}$ to determine cell growth. Three independent experiments were performed for each assay condition.Cell proliferation was measured using a WST-1 kit according to manufacturer's instruction (Roche, Germany).

2.4. Analysis of Intracellular Reactive Oxygen Species. Intracellular reactive oxygen species (ROS) generation was measured with diacetylated $2^{\prime}, 7^{\prime}$-dichlorofluorescein (DCFHDA, Nanjing Jiancheng Bioengineering Institute, China). In brief, $10^{6}$ cells were incubated in $60 \mathrm{~mm}$ plates and, $24 \mathrm{~h}$ later, treated with various compounds, as indicated in the legends to figures. Cells were incubated with $10 \mu \mathrm{M}$ of DCFH-DA for $20 \mathrm{~min}$ at $37^{\circ} \mathrm{C}$, and the DCF fluorescence was measured by flow cytometry (Becton Dickinson FACScan, USA) as previously described in detail [18]. Data were analyzed using Cellquest software (Becton Dickinson). All data are presented as the mean of three independent experiments.

2.5. Hepatic ATP Level. Cells were seeded in 96-well plates $\left(10^{5}\right.$ cells/well). After $24 \mathrm{~h}$, cells were treated as indicated. At the end of the treatments, protein concentrations of the lysates were determined using a bicinchoninic acid protein assay kit (Pierce, Rockford, IL, USA), and ATP content was measured using a CellTiter-Glo2.0 assay kit (Promega, USA).

2.6. Real-Time PCR. Total RNA from cells was extracted using TRIZOL (Invitrogen, Carlsbad, CA, USA). The first strand of cDNA was synthesized from $5 \mu \mathrm{g}$ RNA (Superscript III cDNA Synthesis Kit, Invitrogen). The mRNA for UCP2 and 18S was estimated by quantitative real-time PCR using a SYBR Green PCR Kit (Roche). Quantitative RT-PCR was performed with a Prism 7300 Sequence Detecting System (Applied Biosystems). UCP2 primer sequences were as follows: forward primer 5'-AGCAGTTCTACACCAAGGGC-3', reverse primer $\quad 5^{\prime}$-TGGAAGCGGACCTTTACCAC- $3^{\prime}$ and $18 \mathrm{~s}$ primer sequences were as follows: forward primer $5^{\prime}$ GTAACCCGTTGAACCCCATT- $3^{\prime}$, reverse primer $5^{\prime}$ CCATCCAATCGGTAGTAGCG-3'.

2.7. Immunoblot Analysis. Cells were washed in PBS, and whole-cell extracts were prepared in lysis buffer (Tris- $\mathrm{HCl}$ (20 mM), pH 7.4, NaCl (150 mM), and glycerol (10\% (v/v)), 
Nonidet P-40 (0.2\%), EGTA (1 mM), EDTA (1 mM), PMSF $(1 \mathrm{mM}), \quad \mathrm{NaF} \quad(10 \mathrm{mM})$, leupeptin $(20 \mathrm{mM})$, aprotinin $(5 \mathrm{mg} / \mathrm{mL})$, and sodium orthovanadate $(1 \mathrm{mM}))$ and centrifuged at $8,000 \times \mathrm{g}$ for $15 \mathrm{~min}$. Protein concentrations were measured using the BCA assay (Pierce). Protein $(50 \mu \mathrm{g})$ was separated on a $15 \%(\mathrm{w} / \mathrm{v})$ sodium dodecyl sulphate polyacrylamide gel and then transferred to PVDF membranes (Millipore, Billerica, MA, USA). Membranes were incubated overnight with primary antibodies specific to UCP2 (1:1000, Biolegend), p-AMPK $(1: 2000$, Cell Signaling Technology), caspase-3 (1:1000, Cell Signaling Technology, Beverly MA, USA), and LC3 $(1: 2000$, Cell Signaling Technology) at $4^{\circ} \mathrm{C}$ overnight. The positive reaction against these antibodies was visualized by enhanced chemiluminescence (ECL, Santa Cruz) reagent, followed by exposure to Kodak X-Omat X-ray film. After rinsing the membranes with acetonitrile for $10 \mathrm{~min}$, the membranes were rehybridized with antibodies against $\beta$-actin $(1: 2000$, Cell Signaling Technology) as the loading control. Relative density of protein bands was determined using ImageJ software (National Institutes of Health, USA).

2.8. Overexpression and Silencing of UCP2. UCP2 overexpression experiments were performed using a pcDNA3.1+ expression vector containing the rat CDNA of UCP2 that we designed previously. The cells were transfected with $5 \mu \mathrm{g}$ of either the UCP2-bearing vector or control vector with Lipofectamine 2000 (Roche Diagnostic) following the manufacturer's recommendation. Eight hours after transfection, cells were selected using G418 sulphate $(600 \mu \mathrm{g} / \mathrm{mL})$ for 21 days. The cell colonies resistant to G418 were harvested. Stably expressing UCP2-transfected cells were cultured for further studies. UCP2 silencing experiments were carried out with specific small interfering (si) ( $5^{\prime}$-GUGGUCAAGACGAGAUAUATTUAUAUCUGUCUUGACCACTT- ${ }^{\prime}$ ) RNA targeting UCP2 mRNA and a nontargeting (NT) siRNA $\left(5^{\prime}\right.$ UUCUCCGAACGUGUCACGUTTACGUGACACGUUCGGAGAATT $-3^{\prime}$ ) purchased from Invitrogen Technologies (Shang Hai, China). Cells were transiently transfected with siRNA according to the manufacturer's protocol (Invitrogen Technologies).

2.9. Fluorescence Microscopy. For fluorescence microscopy, cells were cultured in 24-well plates with microscope cover glass. After the designated treatments, cells were fixed with $3 \%(\mathrm{w} / \mathrm{v})$ paraformaldehyde in PBS. For quantification of autophagic cells, LC3 punctate dots were determined from triplicates by counting at least 60 cells. DAPI $(1 \mu \mathrm{g} / \mathrm{mL})$ was used to detect fragmented and condensed nuclei. Images were acquired with a laser scanning confocal microscope (LEICA TCS SP5). Intracellular lipid droplets were stained as previously described [10]. In brief, cells were stained with Nile red at room temperature; then lipid droplets were obtained using an inverted Olympus fluorescence microscope.

2.10. Apoptotic Analysis. Cells were plated in $60 \mathrm{~mm}$ plates. After attachment, cells were incubated with $250 \mu \mathrm{M}$ of PA for $24 \mathrm{~h}$. Cell apoptosis was analyzed using the Annexin VFITC/PI Apoptosis Kit (Biosea, Beijing, China) according to the instructions and measured by flow cytometry. Data are presented as the mean of three determinations. Cells were seeded in 24-well plates. After being treated as indicated, cells were fixed using $4 \%$ paraformaldehyde, and the TUNEL (Promega, USA) manufacturer's protocol was followed. Cells were observed under confocal microscopy and then averaged by the number of TUNEL positive cells/100 cells.

2.11. Statistical Analysis. Data are presented as the mean \pm SD. Analyses were performed using SPSS 13.0 software, and graphs were performed using Prism 5 software. $P$ values $<$ 0.05 or 0.01 are indicated as $(*)$ or $(* *)$, respectively.

\section{Results}

3.1. PA Induces Autophagy Activation. To evaluate the effects of PA on intracellular autophagy in H4IIE cells, we first performed WST-1 assays on H4IIE cells treated with PA at different concentrations and different times. Figure 1(a) shows that treatment with PA resulted in a decrease in the levels of cell growth for up to $24 \mathrm{~h}$ when compared to control cells treated with fatty acid-free BSA (Wako, Japan). As shown in Figure 1(b), cells were stained by Nile red. We observed an increased number of intracellular lipid droplets in H4IIE cells treated with PA compared to BSA. Western blotting revealed a significant increase in the levels of LC3-II for up to $24 \mathrm{~h}$ in comparison to control cells. It is indicated that that PA could increase the levels of LC3-II upon a time course (Figure 1(c)). After inhibition of the late phase of autophagic process by CQ, PA treatment also increased the LC3-II level. However, western blotting revealed that treatment with OA could increase the levels of LC3-II upon a time course (see Supplementary SFigure 4 in Supplementary Material available online at http://dx.doi.org/10.1155/2014/810401), but far more less when compared with the PA-treated cells.

To further confirm the observation that PA treatment does indeed induce autophagy in H4IIE cells, transmission electron microscopy studies were performed under PA treatment (Figure 1(d)). Autophagosome-like vacuoles were hardly seen in BSA-treated control cells. In contrast, we observed an increase in the formation of autophagosome-like structures and lysosomes in PA-treated cells.

3.2. UCP2 Partially Mediated PA-Induced Autophagy. To evaluate if PA treatment could also impact UCP2, we monitored UCP2 mRNA and protein expression by real-time PCR and western blotting. Results revealed that the UCP2 mRNA and protein levels were both increased in H4IIE cells treated with $250 \mu \mathrm{M}$ PA for $6 \mathrm{~h}$ compared to the vehicle control (Figure 2), suggesting that the upregulation of UCP2 expression is mediated by PA in hepatoma cells.

Given that a marked increase in autophagy was observed, we tried to increase intracellular UCP2 expression by UCP2bearing plasmid transfection to ascertain whether antiautophagy effects could be induced following PA treatment. We first performed WST-1 assays on UCP2 overexpression 

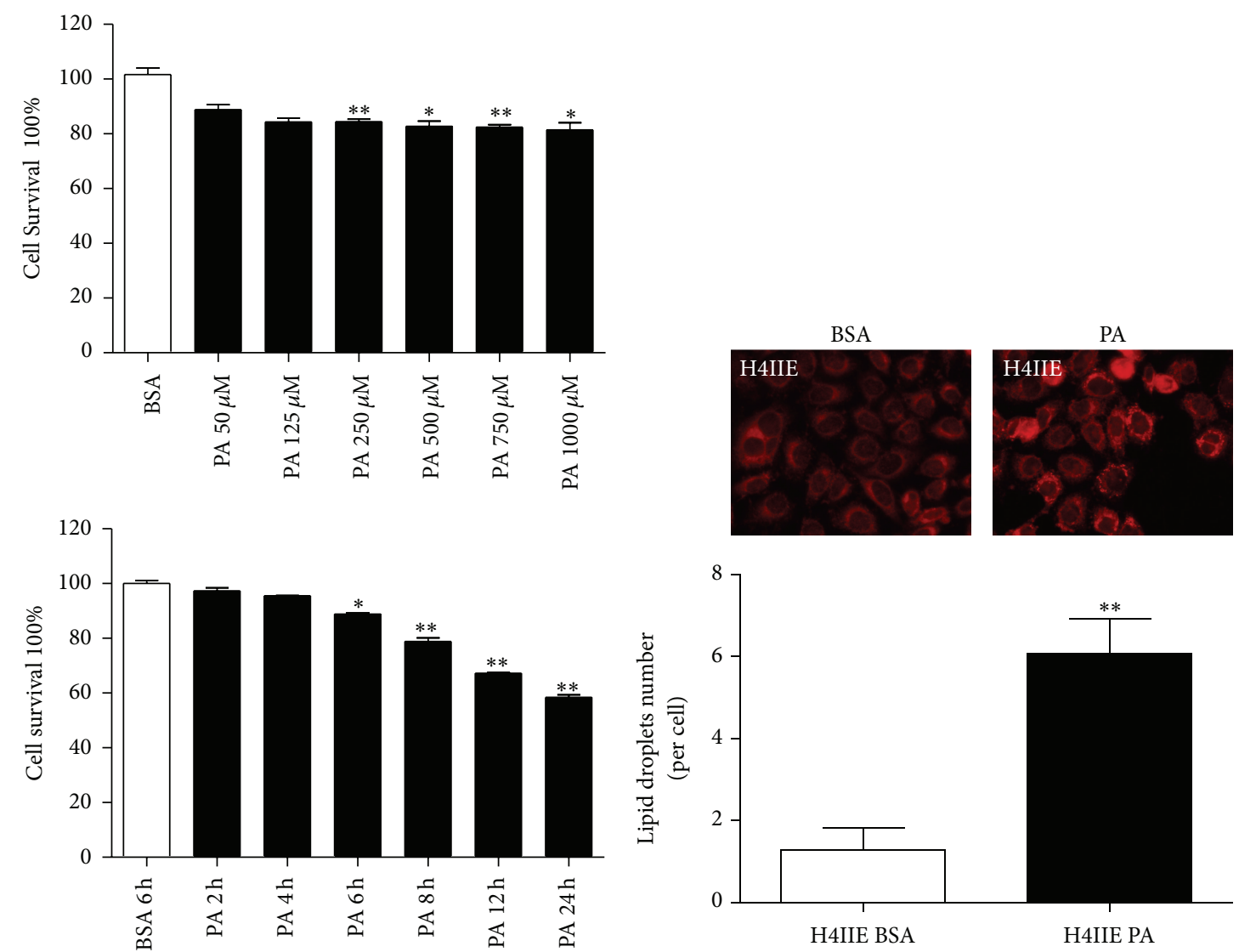

(a)

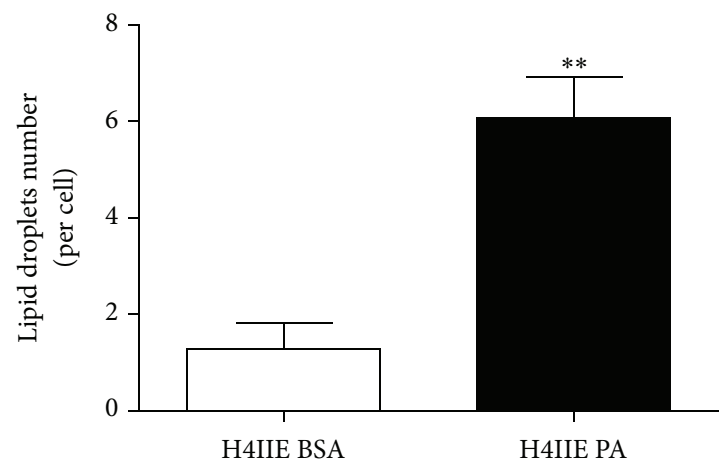

(b)

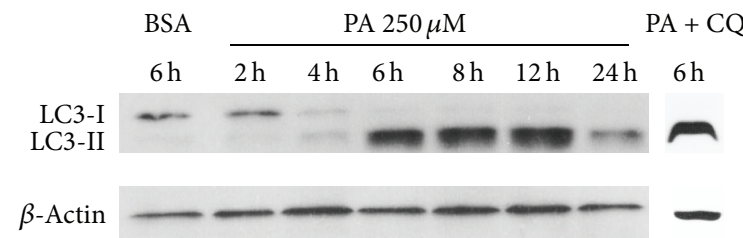

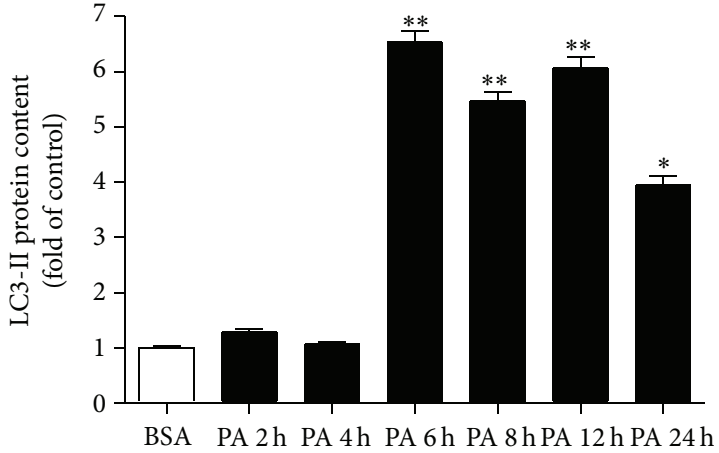

(c)

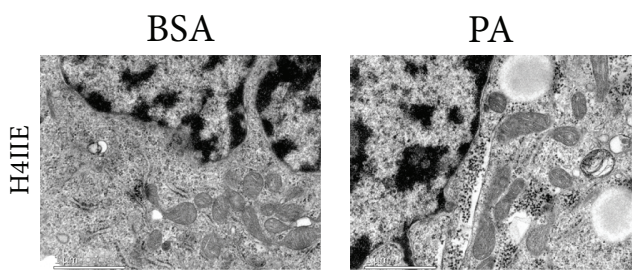

(d)

FIgure 1: PA induces autophagy in H4IIE cells. (a) H4IIE cells were treated with PA $(6 \mathrm{~h})$ conjugated to fatty acid-free BSA at different concentrations, or H4IIE cells were treated with PA $(250 \mu \mathrm{M})$ conjugated to fatty acid-free BSA at different time points. H4IIE cells treated with BSA acted as a control. After treatments, cells were stained and subjected to the WST-1 assay. (b) Intracellular lipid accumulation was assessed with Nile red staining. PA-induced autophagy $(250 \mu \mathrm{M})$ of H4IIE cells exhibited numerous small discrete bodies distributed throughout the cytoplasm (objective lens, $\times 40$ ). (c) H4IIE cells were treated with PA $(250 \mu \mathrm{M})$ conjugated to fatty acid-free BSA for $2,4,6,8,12$, and $24 \mathrm{~h}$ as indicated. Cells treated with BSA acted as a control. After the treatment, cell lysates were collected and subjected to western blotting. (d) H4IIE cells were treated with BSA, PA $(250 \mu \mathrm{M})$, or PA + CQ $(10 \mu \mathrm{M})$ for 6 hours before being processed; then electron microscope was performed at 40,000x magnification. All values are the means \pm SD of three independent experiments each performed in triplicate. 


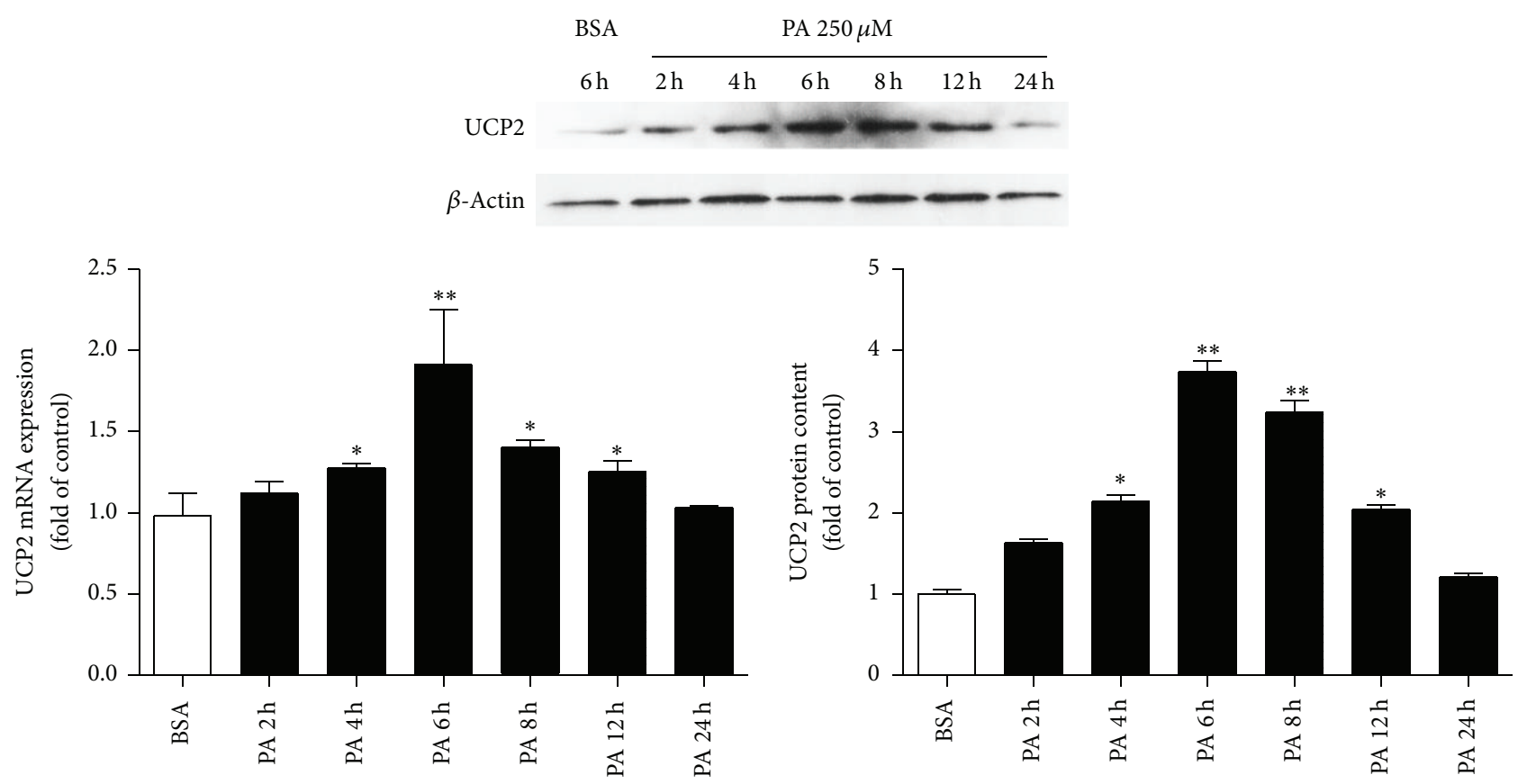

FIgURE 2: The effects of PA on UCP2 expression. H4IIE cells were treated with PA ( $250 \mu \mathrm{M})$ conjugated to fatty acid-free BSA for 2, 4, 6, 8 , 12 , and $24 \mathrm{~h}$ as indicated. The mRNA level of UCP2 was normalized to $18 \mathrm{~s}$. This ratio was set as $100 \%$ with respect to the BSA control. The protein level of UCP2 was normalized to $\beta$-actin, and this ratio was set as $100 \%$ with respect to the BSA control. Data are expressed as the mean \pm SD of three independent experiments each performed in triplicate.

cells treated with PA at different concentrations and different times. It demonstrated that treatment with $\mathrm{PA}$ resulted in a decrease in the levels of cell growth for up to $24 \mathrm{~h}$ when compared to BSA-treated cells (Supplementary SFigure 2). UCP2 expression in cells transfected with the UCP2bearing plasmid was much higher as compared with cells treated with the control vector (Figure 3(a) and Supplementary SFigure 1). First, UCP2 overexpression significantly increased LC3-II levels in cells treated with PA with or without CQ (Figure 3(b)), suggesting that overexpression of UCP2 increased PA-induced autophagy. Furthermore, using inverted fluorescence microscopy (Figure 3(c)), we observed a marked increase of LC3 puncta in PA-treated cells. After all, to investigate autophagosome, electron microscopy analysis was carried out in PA-treated H4IIE cells transfected with the UCP2-bearing plasmid and cells transfected with vectorbearing plasmid acted as a control. As shown in Figure 3(d), more autophagosome structures were observed in UCP2 overexpression cells as compared with control cells by PA treatment under electron microscopy analysis.

To further demonstrate that induction of UCP2 levels is one of the major factors that lead to autophagy following PA treatment, and to confirm the above observations, we next investigated if UCP2 was associated with autophagy in PA-treated cells following UCP2-siRNA transfection. UCP2siRNA markedly decreased UCP2 mRNA and protein levels in cells after being transfected with UCP2-siRNA for 72 hours (Figure 4(a)). It seems that UCP2-siRNA partially decreased LC3-II levels in cells treated with PA (Figure 4(b)), suggesting that inhibition of UCP2 interferes in PA-induced autophagy. These results indicated that deletion of UCP2 could decrease the effect of PA on LC3 puncta formation, suggesting a positive effect of UCP2 in PA-induced hepatic carcinoma cells autophagy.

3.3. PA-Mediated ROS Production Is Partially UCP2 Dependent. To evaluate the effect of UCP2 on intracellular ROS production, we performed ROS assays on H4IIE cells that were overexpressed UCP2 or inhibited by UCP2 siRNA and genipin. We observed that treatment with PA up to $6 \mathrm{~h}$ resulted in a significant increase in ROS production as compared with the BSA-treated control cells using the DCFH-DA assay by flow cytometry (Figures 5(a)-5(c)). This observation was further validated under fluorescence microscopy as shown in Figures 5(d)-5(f). As shown in Figure 5, UCP2 overexpression cells treated with PA resulted in a significant decrease (about 65\%) in ROS production as compared with the vector-Tr cells, although overexpressed UCP2 decreases ROS levels in BSA treatments. After inhibiting UCP2 expression, the ROS production of H4IIE cells that were treated with $\mathrm{PA}$ increased $60 \%$ as compared with the scramble cells. But in BSA treatments the increased ratio is only $40 \%$. Notably, the addition of CQ markedly enhanced ROS production induced by PA in three treatments (overexpression, siRNA, and genipin). However, the addition of CQ to the BSA control cells for up to $6 \mathrm{~h}$ did not induce any significant decrease in cell viability, suggesting that CQ alone is not cytotoxic to the H4IIE cells (Figures 5(a)-5(c)).

3.4. PA and UCP2 Mediate ATP Synthesis. To evaluate the effects of UCP2 on AMPK activation and ATP synthesis, we 


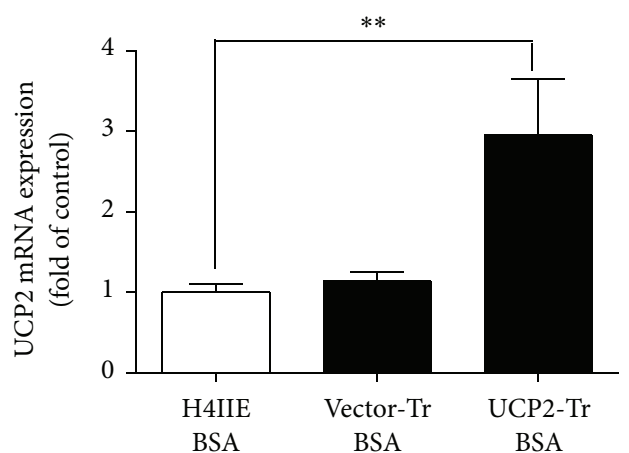

BSA

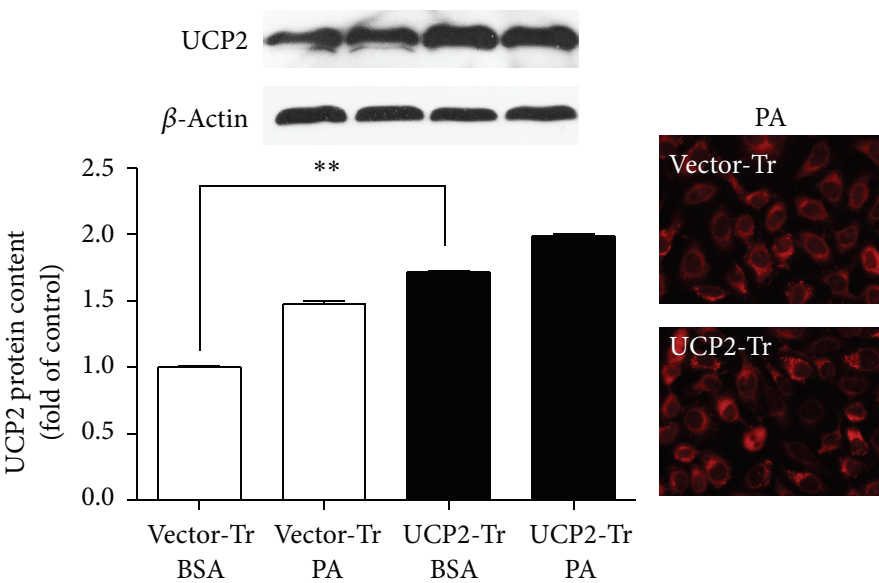

(a)

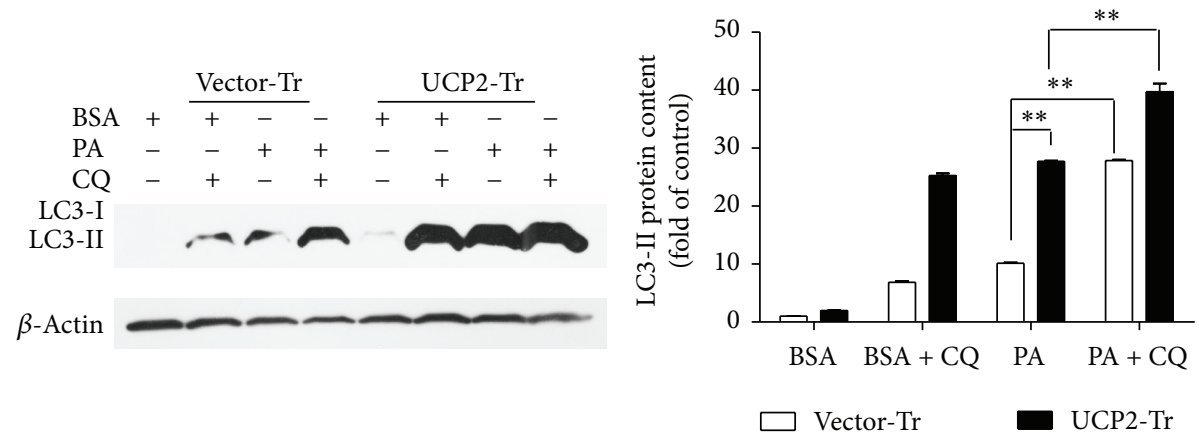

(b)
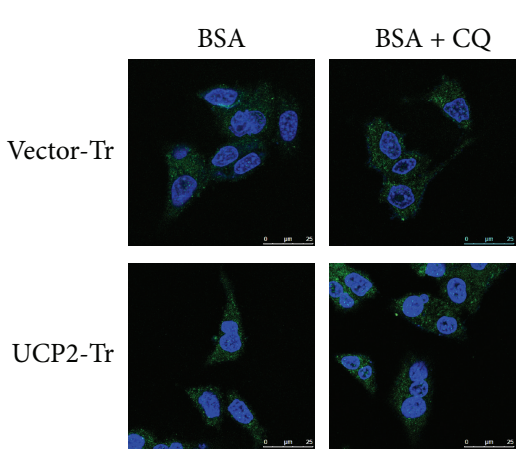
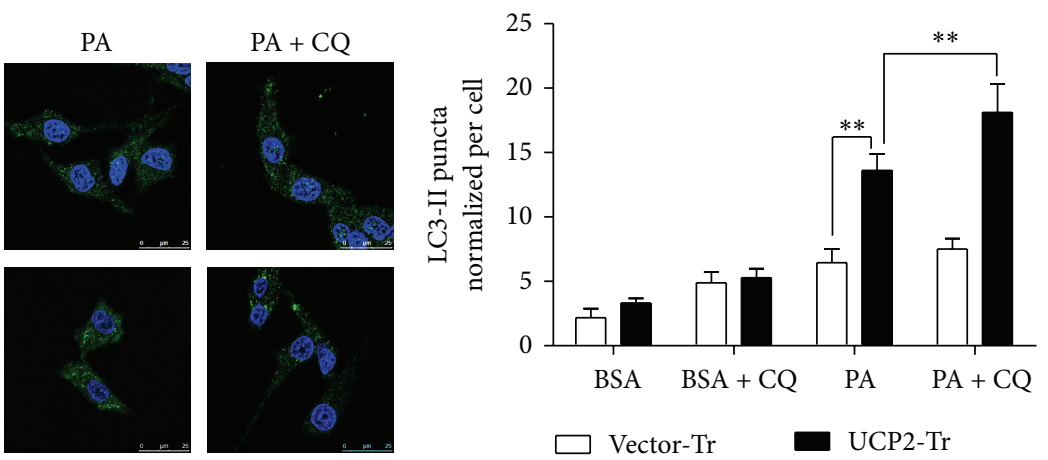

(c)

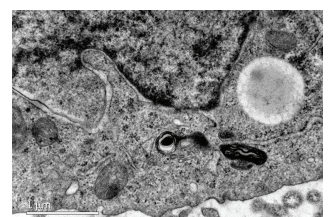

Vector-Tr PA

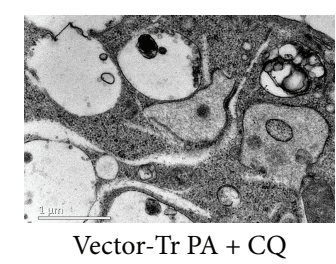

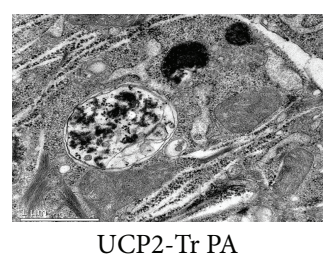

UCP2-Tr PA

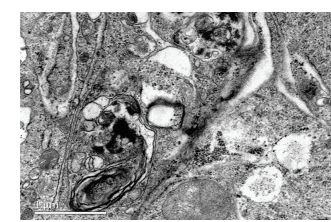

$\mathrm{UCP} 2-\operatorname{Tr} \mathrm{PA}+\mathrm{CQ}$

(d)

FIGURE 3: UCP2 overexpression enhanced PA-mediated autophagy. H4IIE cells were transfected with UCP2-bearing plasmid and control vector plasmid and then treated with $250 \mu \mathrm{M}$ PA for $6 \mathrm{~h}$, with or without CQ $(10 \mu \mathrm{M})$. (a) The level of UCP2 mRNA was normalized to $18 \mathrm{~s}$, and UCP2 protein was normalized to $\beta$-actin. This ratio was set to $100 \%$ in the control of BSA. (b) The level of LC3 protein was normalized to $\beta$-actin, and this ratio was set to $100 \%$ in the control of BSA. (c) H4IIE cells were treated with $250 \mu \mathrm{M}$ PA for 6 h. Then LC3 puncta formation was observed using an inverted fluorescence microscope. The numbers of LC3 puncta/cell were counted from $\geq 100$ cells. (d) Cells were treated with PA $(250 \mu \mathrm{M})$ for $6 \mathrm{~h}$, with or without CQ before being processed; then electron microscope was performed at 40,000x magnification. Data are expressed as the mean \pm SD for each experiment. All data presented are representative of three separate experiments with consistent results. 


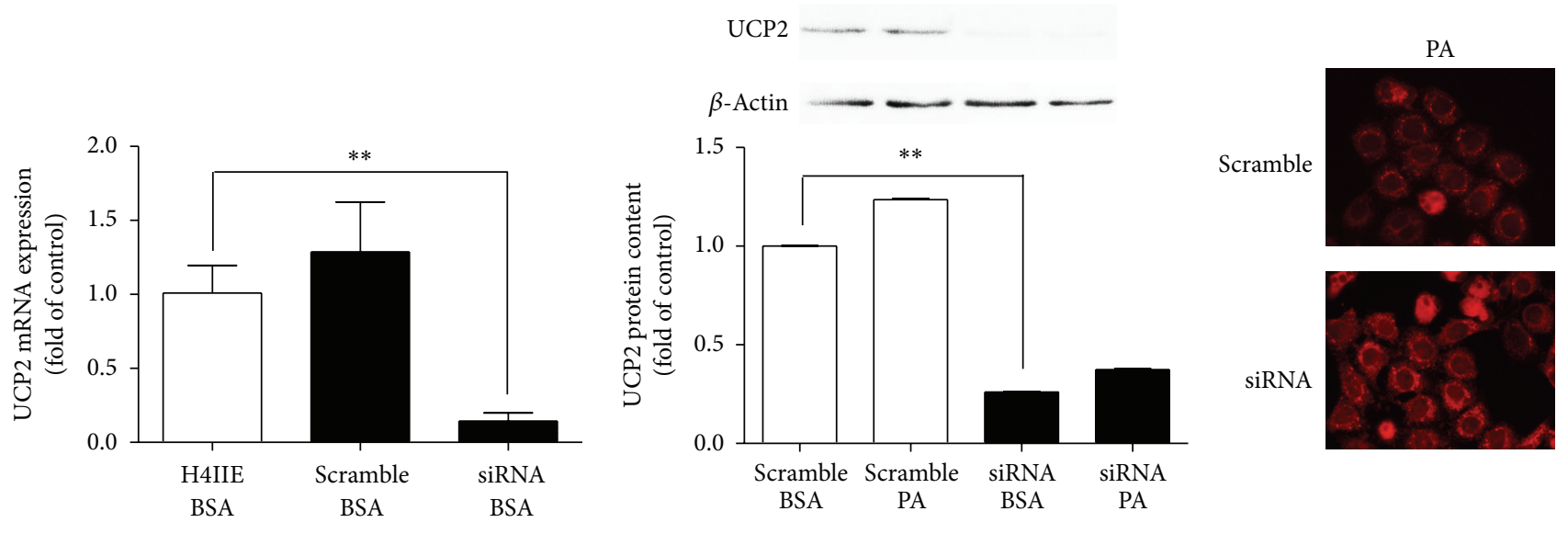

(a)

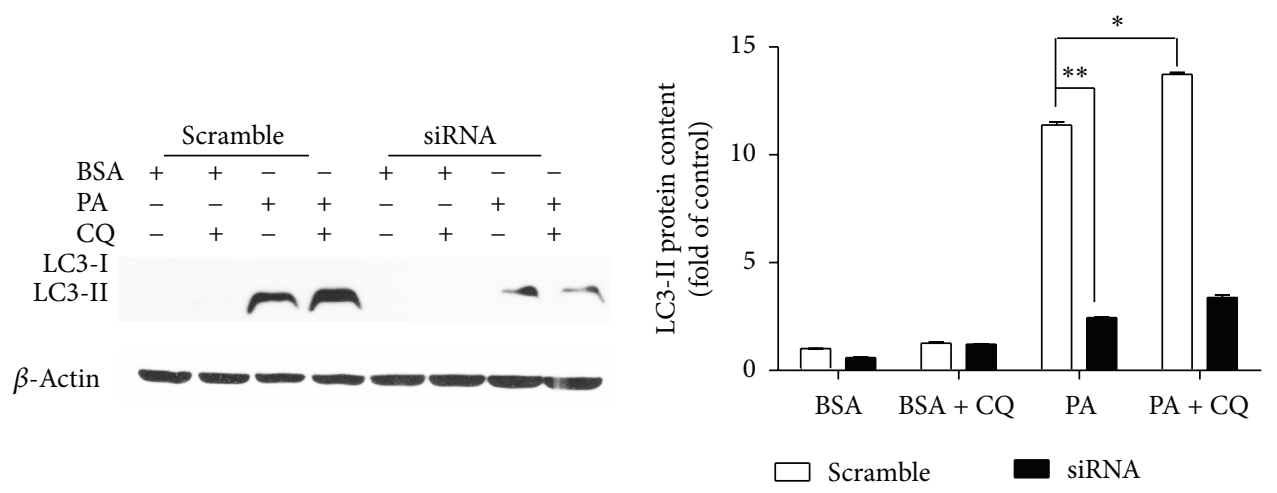

(b)
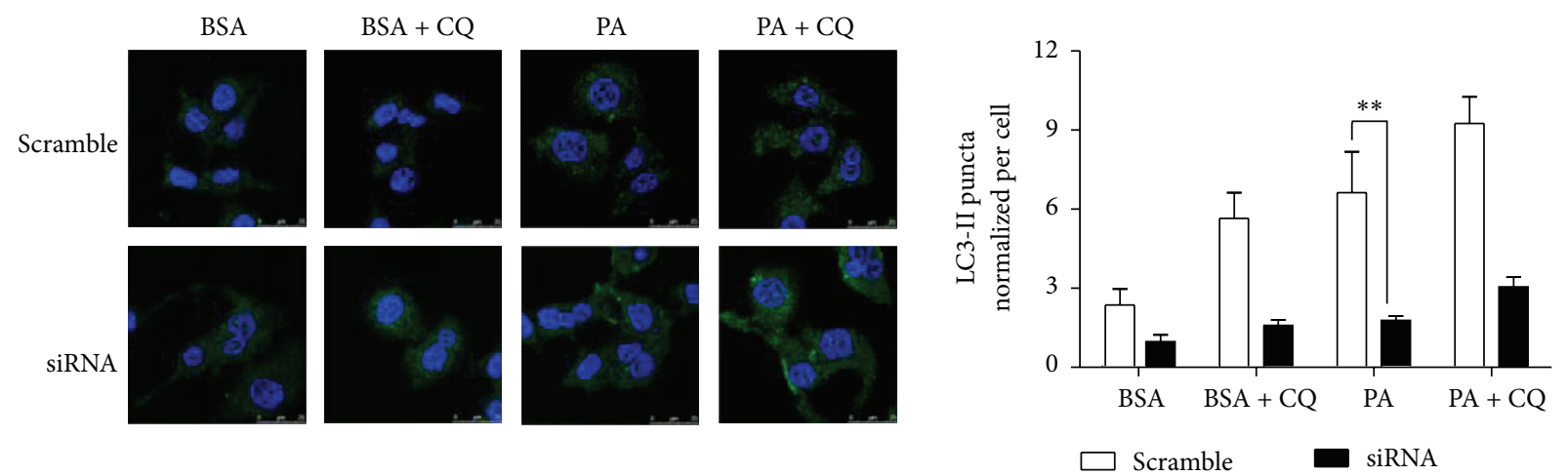

(c)

FIGURE 4: Inhibition of UCP2 decreases PA-mediated autophagy. H4IIE cells were transfected with UCP2-siRNA for $72 \mathrm{~h}$ to inhibit the expression of UCP2, followed by $250 \mu \mathrm{M}$ PA for $6 \mathrm{~h}$, with or without CQ $(10 \mu \mathrm{M})$. (a) The level of UCP2 mRNA was normalized to $18 \mathrm{~s}$, and UCP2 protein was normalized to $\beta$-actin. This ratio was set to $100 \%$ in the control of BSA. (b) The level of LC3 protein was normalized to $\beta$ actin, and this ratio was set to $100 \%$ in the control of BSA. (c) H4IIE cells were transfected with UCP2 siRNA for $72 \mathrm{~h}$, followed by $250 \mu \mathrm{M}$ PA for $6 \mathrm{~h}$. Then LC3 puncta formation was observed using an inverted fluorescence microscope. The numbers of LC3 puncta/cell were counted from $\geq 100$ cells. (d) Cells were treated with PA $(250 \mu \mathrm{M})$ for $6 \mathrm{~h}$, with or without CQ before being processed; then electron microscope was performed at 40,000x magnification. Data are expressed as the mean \pm SD for each experiment. All data presented are representative of three separate experiments with consistent results.

performed ATP assays. Figure 6(a) indicated that overexpression of UCP2 could decrease intracellular ATP synthesis. In addition, Figure 6(b) demonstrated that ATP synthesis was inc-reased in UCP2 silencing H4IIE cells. Figure 6 showed that PA treatment could also decrease intracellular ATP synthesis. UCP2 overexpression or silencing could mediate AMPK activation to some level, but this phenomenon seemed so complicated that needs to be further studied. 


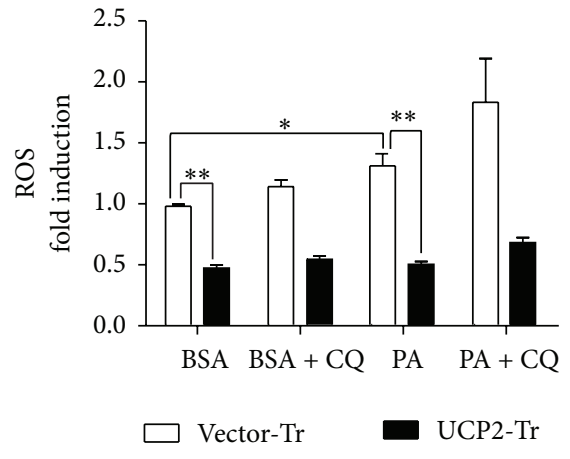

(a)

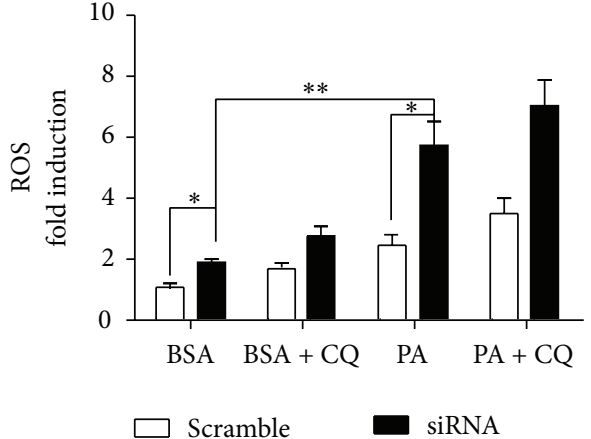

(b)

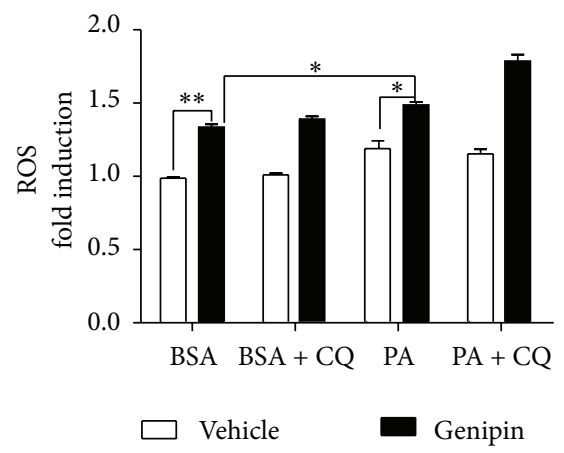

(c)

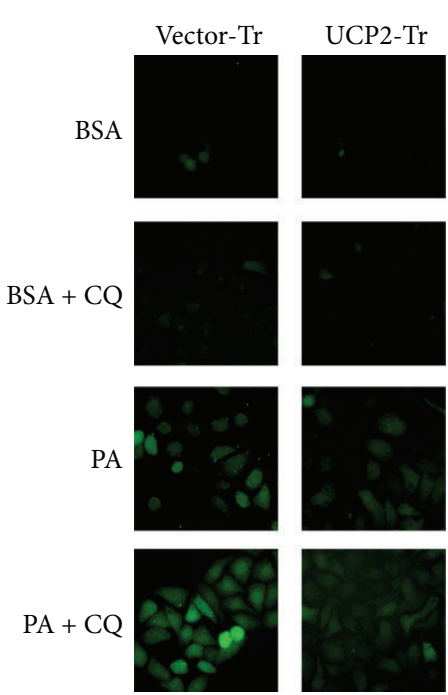

(d)

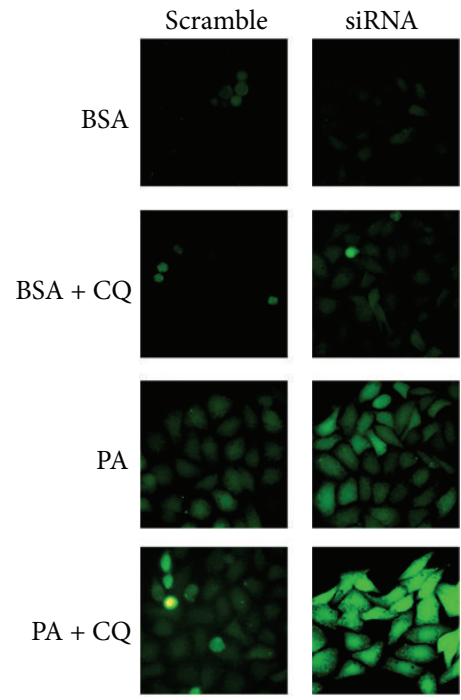

(e)

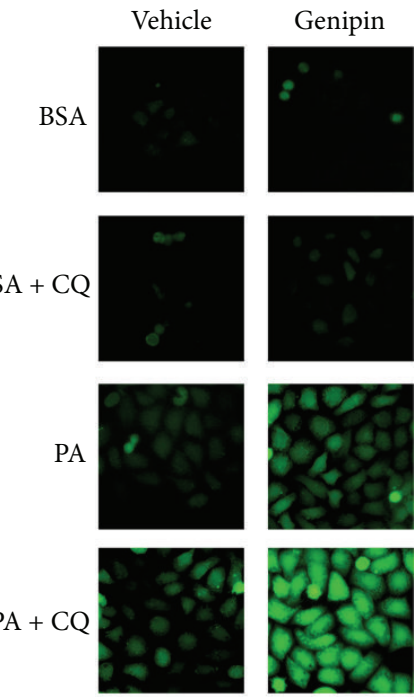

(f)

FIGURE 5: PA-mediated intracellular ROS production is UCP2 mediated. (a) H4IIE cells were transfected with UCP2 plasmid (UCP2-Tr) or control vector (Vector-Tr). Intracellular ROS production induced by $250 \mu \mathrm{MPA}$ for $6 \mathrm{~h}$ was assessed using DCFH-DA and analyzed by flow cytometry. (b) H4IIE cells were transfected with UCP2 siRNA (UCP2-siRNA) or scrambled siRNA (Scramble) for $72 \mathrm{~h}$ to inhibit the expression of UCP2 and treated with PA. (c) H4IIE cells were treated with $50 \mu \mathrm{M}$ genipin for $24 \mathrm{~h}$, followed by PA, with or without CQ $(10 \mu \mathrm{M})$. (d)-(f) Intracellular ROS was assessed using DCFH-DA staining and microscopy. Data are expressed as the mean \pm SD for each experiment. All data presented are representative of three separate experiments with consistent results.

3.5. UCP2 Has an Antiapoptotic Effect on PA-Induced Apoptosis. Recent studies have shown that PA possesses cytotoxic properties [19, 20]. Our latest study has also shown marked cell apoptosis in livers during NASH progression [10]. To further investigate the physiological relevance of UCP2 in the progress of NASH, we treated H4IIE cells with $250 \mu \mathrm{M}$
PA for up to $24 \mathrm{~h}$. The results showed a significant increase in the number of apoptotic cells when treated with PA compared to BSA-treated cells (Figure 7(a)). It suggested that UCP2 expression may serve as a protective mechanism against lipotoxicity. To assess the relationship between cellular apoptosis and UCP2, we performed the TUNEL assay. 

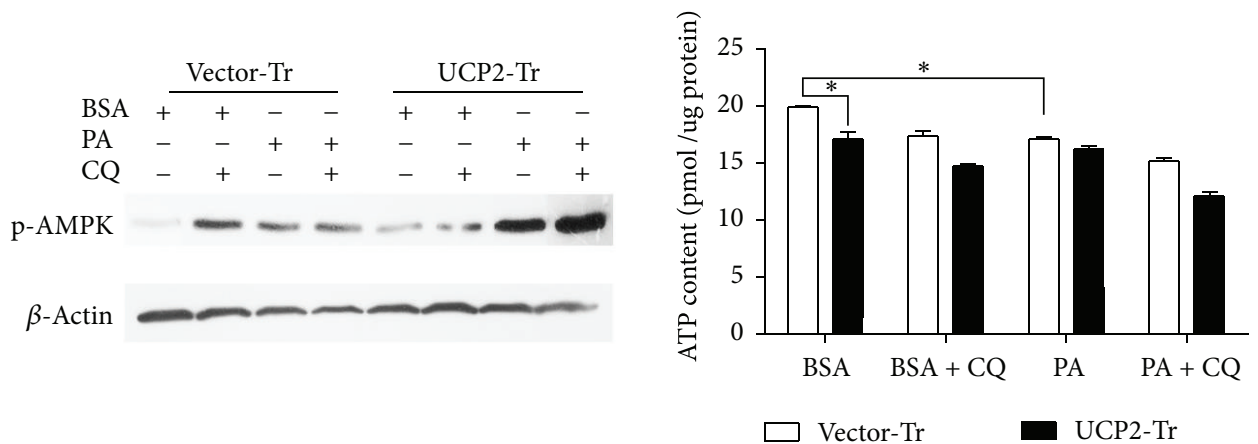

(a)
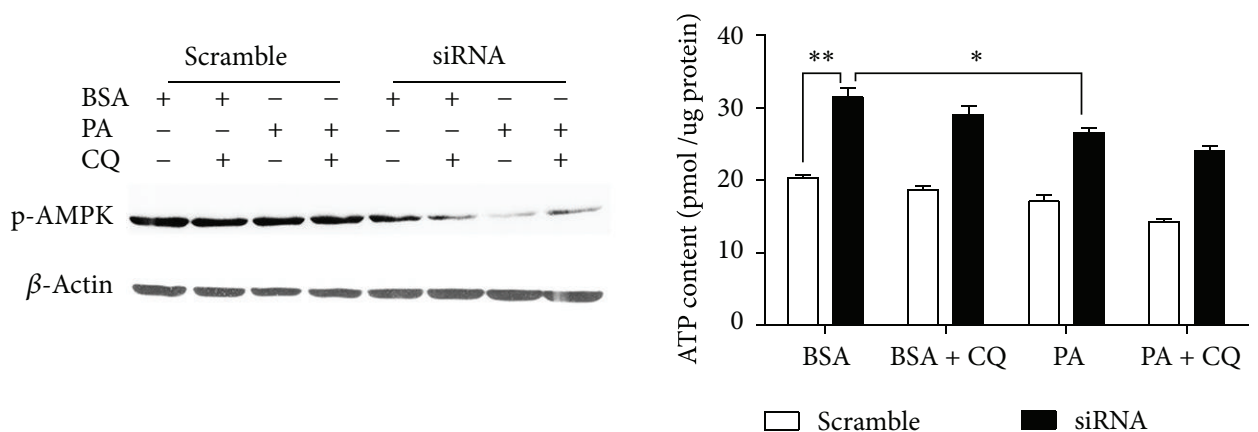

(b)

FIgURE 6: UCP2- and PA-mediated ATP synthesis. (a) H4IIE cells were transfected with UCP2 plasmid (UCP2-Tr) or control vector (VectorTr). ATP induced by $250 \mu \mathrm{M}$ PA for $6 \mathrm{~h}$ was assessed using CellTiter-Glo2.0 assay kit, and p-AMPK was normalized to $\beta$-actin. This ratio was set to $100 \%$ in the control of BSA. (b) H4IIE cells were transfected with UCP2 siRNA (UCP2-siRNA) or scrambled siRNA (scramble) for $72 \mathrm{~h}$ to inhibit the expression of UCP2 and treated with PA. ATP induced by $250 \mu \mathrm{M}$ PA for $6 \mathrm{~h}$ was assessed using CellTiter-Glo2.0 assay kit, and p-AMPK was normalized to $\beta$-actin. This ratio was set to $100 \%$ in the control of BSA. Data are expressed as the mean \pm SD for each experiment. All data presented are representative of three separate experiments with consistent results.

PA treatment significantly promoted apoptosis in H4IIE cells, as the numbers of TUNEL-positive cells increased at PA treatments (Figure $7(\mathrm{~b})$ ). The same results further confirm that UCP2 plays an antiapoptotic role in PA stimulus. As shown in Figure 7(c), there were higher levels of cleaved caspase-3 in vehicle control cells, which indicated that UCP2 may play an antiapoptotic role and inhibit lipotoxic stress.

As shown in Figure 7, the addition of CQ also enhanced cell death. The addition of CQ enhanced cell death induced by PA. As shown in the BSA control cells, the addition of CQ induced an increase in cell apoptosis. It suggests that autophagy may act as a protective mechanism against apoptosis. This possibility has been reported in a previous study [21], and our data demonstrated a similar mechanism in hepatic carcinoma cells. We observed that treatment with PA resulted in a significant increase in apoptosis as compared with the BSA-treated control cells (Figure 7(a)). This observation was further validated under TUNEL assay as shown in Figure 7(b). As shown in Figure 7, UCP2 overexpression cells treated with PA resulted in a significant decrease (about 200\%) in apoptotic cells as compared with the Vector-Tr cells. After inhibiting UCP2 expression, the apoptosis ratio of H4IIE cells that were treated with PA increased $40 \%$ as compared with the scramble cells. Notably, the addition of CQ markedly enhanced apoptosis ratio induced by PA in both treatments (overexpression and siRNA). However, the addition of CQ to the BSA control cells did not induce any significant decrease in cell viability, suggesting that CQ alone is not cytotoxic to the H4IIE cells (Figures 5(a)-5(c)).

\section{Discussion}

Lipotoxicity has been thought to be the main contributor to the progression of various diseases associated with excess lipid accumulation in the body, such as obesity and steatohepatitis [22]. The autophagic process has been well documented as a cell survival mechanism and has been implicated in several diseases such as cancer and neurodegenerative diseases $[23,24]$. At present, autophagy has been shown to have a role in regulating lipid metabolism. The inhibition of autophagy in cultured hepatocytes and the mouse liver has been shown to increase triglyceride storage in lipid droplets [11], and it is known that PA can regulate autophagic activity in hepatocytes [25]. In this study, we reproved evidence that autophagy can be induced by the saturated fatty acid PA in H4IIe cells. Meanwhile, we showed that autophagy induction by PA is dependent on UCP 2 activity. Furthermore, we also present evidence that autophagy plays a prosurvival 

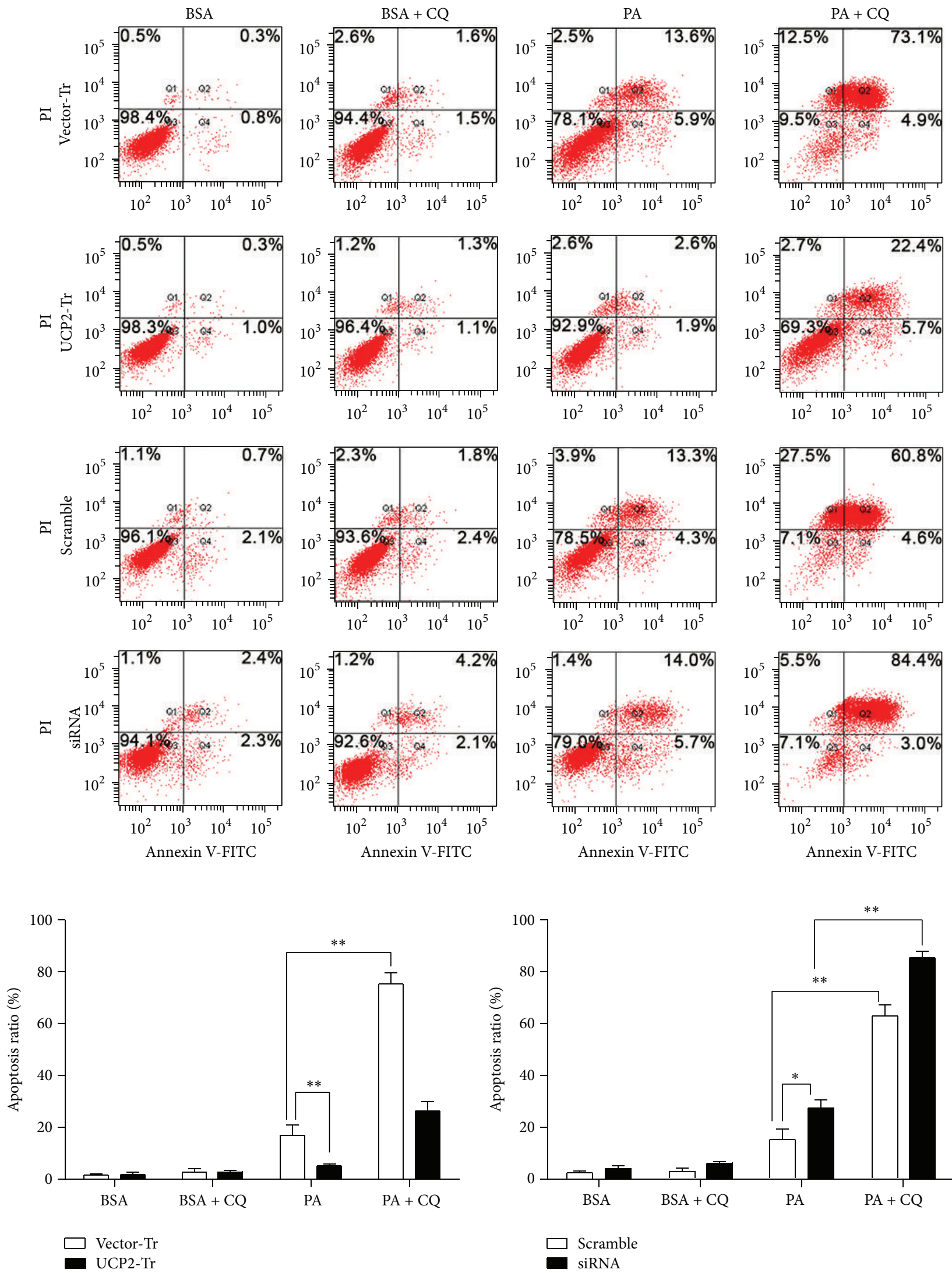

(a)

Figure 7: Continued. 

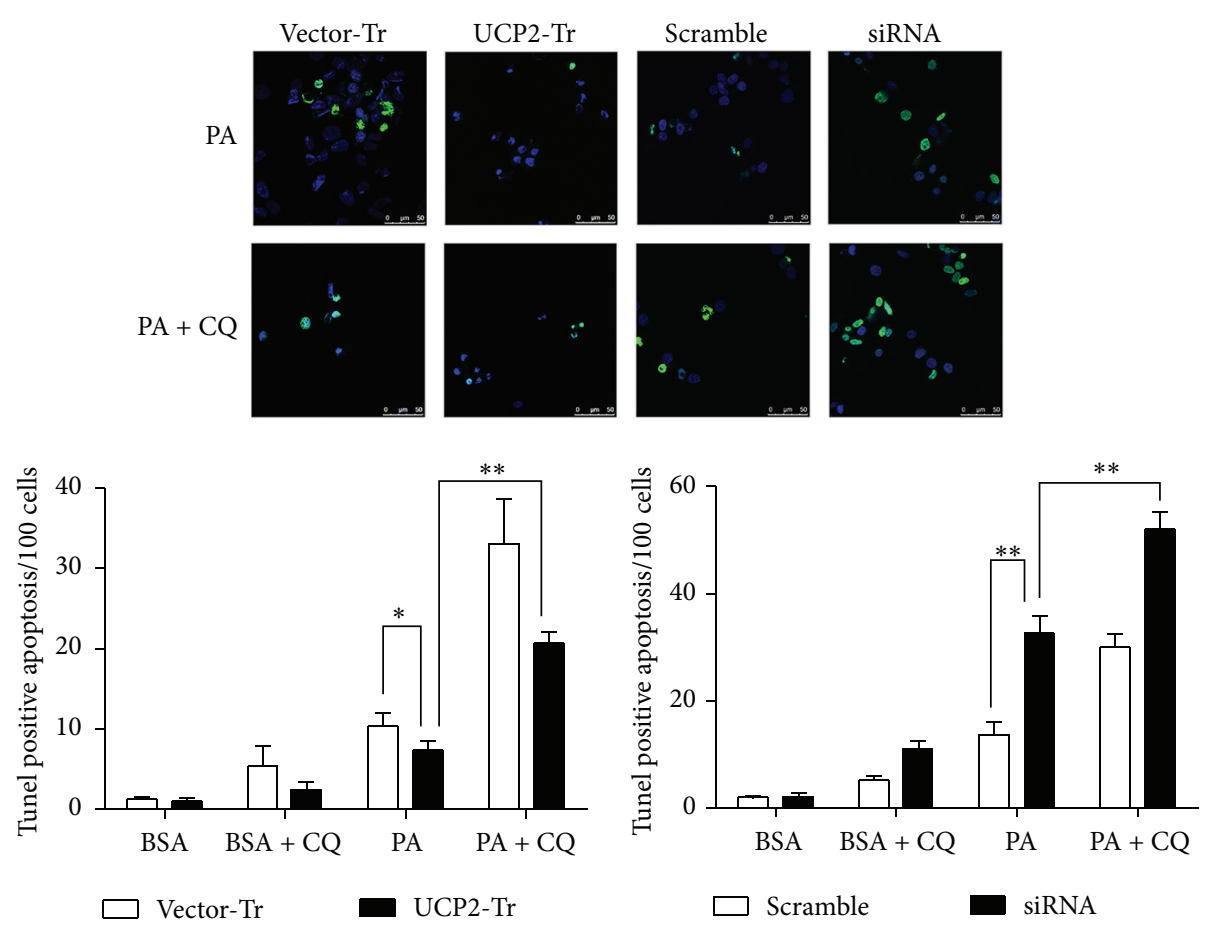

(b)
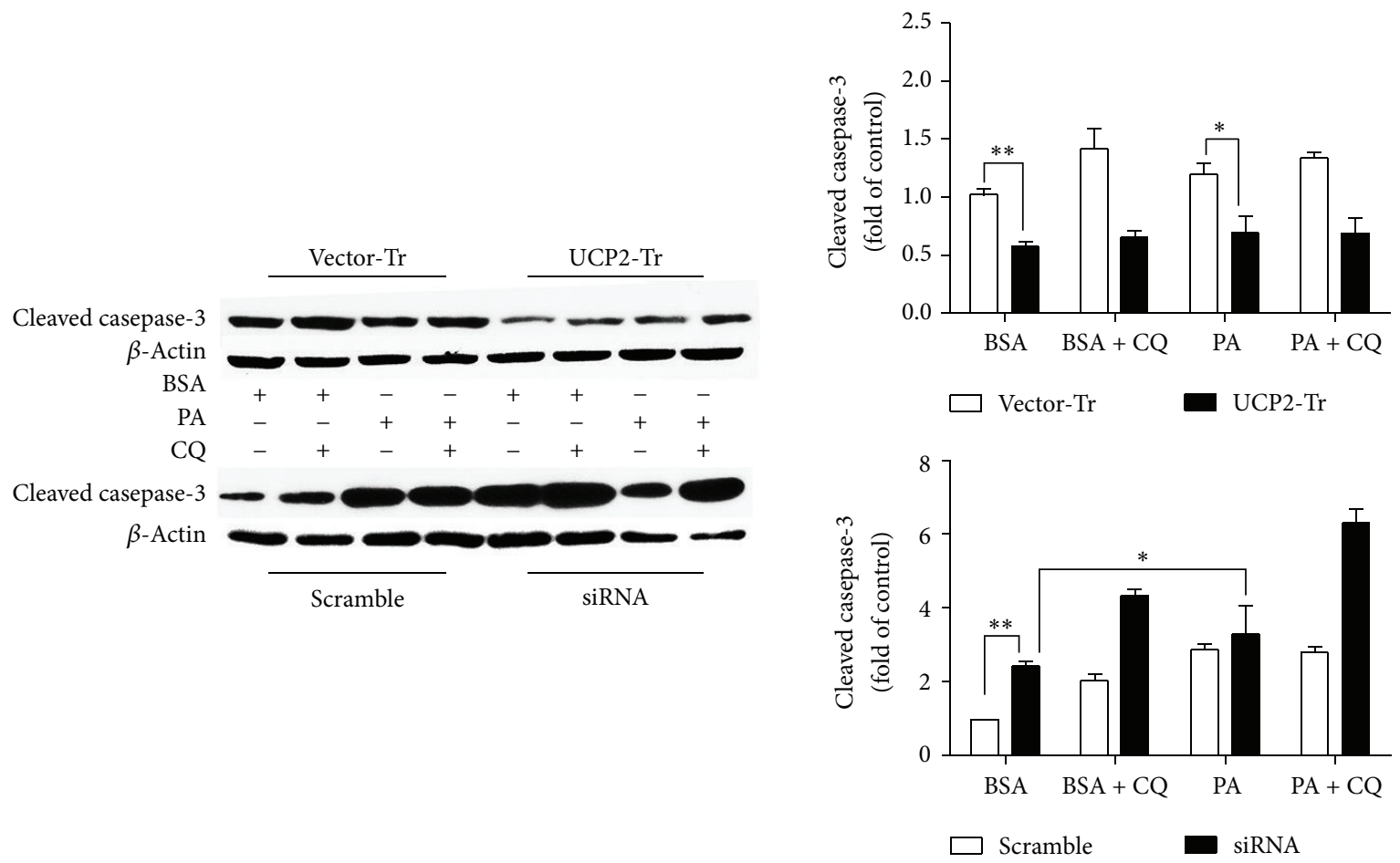

(c)

FIGURE 7: UCP2 has an antiapoptotic effect in PA-induced apoptosis. H4IIE cells were transfected with UCP2-bearing plasmid and UCP2siRNA and then treated with $250 \mu \mathrm{M}$ PA for $24 \mathrm{~h}$. (a) Cellular apoptosis induced by $250 \mu \mathrm{M}$ PA was analyzed by flow cytometry. Data are expressed as the mean \pm SD for each experiment. (b) TUNEL-positive cells that were green under fluorescence microscopy were quantified from 100 cells at $\times 400$ magnifications. Data were expressed as the mean \pm SD for each experiment. (c) Representative of cleaved caspase-3 and $\beta$-actin proteins expression by western blot. Data were expressed as the mean \pm SD. All data presented are representative of three separate experiments with consistent results. 
function to protect against PA-induced lipotoxicity. Our findings are generally consistent with earlier reports that $\mathrm{PA}$ is capable of inducing autophagy in pancreatic $\beta$-cells $[26,27]$ and embryonic fibroblasts [21]. In a recent study, it has been reported that autophagy can be induced by PA, but not by OA [21]. On the other hand, it is believed that only OA but not PA was capable of inducing autophagy in hepatocytes [28]. One study has also reported that PA prevented fusion of autophagosomes and lysosomes and thus inhibited autophagy [29]. It is believed that cell type, concentration, duration of FFA treatment, and the ratio of conjugated BSA to FFA used could be attributed to these conflicting results.

$\mathrm{UCP} 2$ is one of the mitochondrial transporters that are located in the inner mitochondrial membrane and belong to a family of mitochondrial anion carriers, which includes adenine nucleotide transporters. Mild uncoupling of respiration has been reported to diminish mitochondrial reactive oxygen species (ROS) formation [30]. It has been demonstrated that upregulation of UCP2 by AMPK activation attenuates oxidative stress [31]. A recent study also shows that AMPK is an upstream kinase for UCP2 [32]. Our results indicate that UCP 2 could decrease intracellular ATP synthesis, and PA stimuli may partially decrease the level of intracellular ATP synthesis. UCP2 is rather an upstream kinase for AMPK than feedback to AMPK activation.

It is well known that UCP2 is an antioxidant mitochondrial protein and that inhibition of UCP2 induces oxidative stress favoring the formation of mitochondrial superoxide ions [33]. Recently, it has been demonstrated that UCP2 is a key redox-sensitive protein [34]. Overexpression of UCP2 decreases cell death following downregulation of ROS production [35]. This aspect of UCP2 function further strengthens the proposition that UCP2 can modulate mitochondrial ROS production and activity. In the present study, we clearly elucidate for the first time the role of UCP2-mediated mitochondrial uncoupling on autophagy regulation in hepatocyte ROS production. The results showed that high UCP2expressing H4IIE cells have more enhanced adaptive abilities to PA-induced lipotoxicity partly through diminishing ROS production than low UCP2-expressing cells. Because CQ is known to block autophagy by suppressing the lysosomal function, our findings thus indicate that UCP2 may protect against PA-mediated autophagy on ROS production. This aspect of UCP2 function further strengthens the proposition that UCP2 can modulate mitochondrial ROS production and activity [36]. Here, we confirmed that ROS production is mediated by UCP2 after PA-induced hepatocyte lipotoxicity.

Autophagy is a critical intracellular pathway that targets cell constituents to the lysosome for degradation. Recent studies showed that established functions for both macroautophagy and chaperone-mediated autophagy in hepatic lipid metabolism, insulin sensitivity, and cellular injury suggest a number of potential mechanistic roles for autophagy in NASH [15]. Decreased autophagic function in particular may promote the initial development of hepatic steatosis and progression of steatosis to liver injury [15]. In the present study, we observed that UCP2 overexpression also significantly increased autophagy in PA-treated cells, while inhibition of UCP2 resulted in a decrease in PA-induced autophagy. Furthermore, with loss of autophagic function, decreased lipid storage occurred, and an increased rate of fatty acid $\beta$-oxidation was observed [12]. We suspect that PAinduced autophagy occurred partly through increased UCP2 upregulation.

In this study, we have shown that UCP2 is associated with apoptosis induced by fatty acids in vitro. Our previous study has shown that PA was able to induce liver damage that resembles NAFLD in humans and was characterized by increasing caspase-3 activity and prominent apoptosis [10]. To further confirm these results, we altered UCP2 expression levels in H4IIE hepatoma cells by transfection with either an UCP2 mRNA interference (siRNA) plasmid or a UCP2overexpressing plasmid. UCP2 overexpression caused significantly decreased apoptosis rates and caspase- 3 activity in the PA-treated cells while UCP2 siRNA resulted in an increase in apoptosis rates and caspase-3 activity. Overall, we have demonstrated that UCP2 protects hepatic carcinoma cells from PA-induced apoptosis in vitro by increasing hepatocyte autophagy. We predict that the antiapoptotic effect of UCP2 most likely relates to its preventative role in its inductive effect of hepatoma autophagy.

\section{Conclusion}

Our present study shows that UCP2 was upregulated and that hepatocellular autophagy was increased during PA treatment. Increasing UCP2 expression in hepatoma cells may contribute to cell autophagy. Hepatic autophagy play a protective role in hepatocyte lipoapoptosis. The results provide evidence that UCP2 is a proliferative factor that also has an antiapoptotic role during PA-induced liver injury. The current data obtained from our experiments may provide useful information regarding potential molecular targets for NASH prevention and treatment.

\section{Abbreviations \\ ROS: Reactive oxygen species \\ UCP2: Uncoupling protein 2 \\ NAFLD: Nonalcoholic fatty liver disease \\ NASH: Nonalcoholic steatohepatitis \\ FFA: $\quad$ Free fatty acid \\ PA: $\quad$ Palmitic acid \\ CQ: Chloroquine diphosphate.}

\section{Conflict of Interests}

The authors declare that there is no conflict of interests regarding the publication of this paper.

\section{Acknowledgments}

This work was supported by the National Natural Science Foundation of China (81070319) and the Beijing Natural Science Foundation of China (7102013). 


\section{References}

[1] S. Krauss, C. Y. Zhang, and B. B. Lowell, "The mitochondrial uncoupling-protein homologues," Nature Reviews Molecular Cell Biology, vol. 6, no. 3, pp. 248-261, 2005.

[2] G. Baffy, "Uncoupling protein-2 and non-alcoholic fatty liver disease," Frontiers in Bioscience, vol. 10, no. 9, pp. 2082-2096, 2005.

[3] C. Fleury and D. Sanchis, "The mitochondrial uncoupling protein-2: current status," The International Journal of Biochemistry and Cell Biology, vol. 31, no. 11, pp. 1261-1278, 1999.

[4] A. V. Medvedev, S. K. Snedden, S. Raimbault, D. Ricquier, and S. Collins, "Transcriptional regulation of the mouse uncoupling protein-2 gene: double E-box motif is required for peroxisome proliferator-activated receptor- $\gamma$-dependent activation," The Journal of Biological Chemistry, vol. 276, no. 14, pp. 1081710823, 2001.

[5] A. V. Medvedev, J. Robidoux, X. Bai et al., "Regulation of the uncoupling protein- 2 gene in INS-1 $\beta$-cells by oleic acid," Journal of Biological Chemistry, vol. 277, no. 45, pp. 4263942644, 2002.

[6] M. F. McCarty, "High mitochondrial redox potential may promote induction and activation of UCP2 in hepatocytes during hepatothermic therapy," Medical Hypotheses, vol. 64, no. 6, pp. 1216-1219, 2005.

[7] P. Collins, C. Jones, S. Choudhury, L. Damelin, and H. Hodgson, "Increased expression of uncoupling protein 2 in HepG2 cells attenuates oxidative damage and apoptosis," Liver International, vol. 25, no. 4, pp. 880-887, 2005.

[8] E. Dalla Pozza, C. Fiorini, I. Dando et al., "Role of mitochondrial uncoupling protein 2 in cancer cell resistance to gemcitabine," Biochimica et Biophysica Acta (BBA)-Molecular Cell Research, vol. 1823, no. 10, pp. 1856-1863, 2012.

[9] B. A. Neuschwander-Tetri, "Hepatic lipotoxicity and the pathogenesis of nonalcoholic steatohepatitis: the central role of nontriglyceride fatty acid metabolites," Hepatology, vol. 52, no. 2, pp. 774-788, 2010.

[10] Y. Jiang, M. Zhao, and W. An, "Increased hepatic apoptosis in high-fat diet-induced NASH in rats may be associated with downregulation of hepatic stimulator substance," Journal of Molecular Medicine, vol. 89, no. 12, pp. 1207-1217, 2011.

[11] R. Singh, S. Kaushik, Y. Wang et al., "Autophagy regulates lipid metabolism," Nature, vol. 458, no. 7242, pp. 1131-1135, 2009.

[12] R. Singh, Y. Xiang, Y. Wang et al., "Autophagy regulates adipose mass and differentiation in mice," Journal of Clinical Investigation, vol. 119, no. 11, pp. 3329-3339, 2009.

[13] Q. Q. Tu, R. Y. Zheng, J. Li et al., "Palmitic acid induces autophagy in hepatocytes via JNK2 activation," Acta Pharmacologica Sinica, vol. 35, no. 4, pp. 504-512, 2014.

[14] Y. Kabeya, N. Mizushima, A. Yamamoto, S. Oshitani-Okamoto, Y. Ohsumi, and T. Yoshimori, "LC3, GABARAP and GATE16 localize to autophagosomal membrane depending on form-II formation," Journal of Cell Science, vol. 117, no. 13, pp. 2805-2812, 2004.

[15] M. Amir and M. J. Czaja, "Autophagy in nonalcoholic steatohepatitis," Expert Review of Gastroenterology and Hepatology, vol. 5, no. 2, pp. 159-166, 2011.

[16] I. Dando, C. Fiorini, E. D. Pozza et al., "UCP2 inhibition triggers ROS-dependent nuclear translocation of GAPDH and autophagic cell death in pancreatic adenocarcinoma cells," Biochimica et Biophysica Acta-Molecular Cell Research, vol. 1833, no. 3, pp. 672-679, 2013.
[17] Y. Yang, Y. Jiang, Y. Wang, and W. An, "Suppression of ABCA1 by unsaturated fatty acids leads to lipid accumulation in HepG2 cells," Biochimie, vol. 92, no. 8, pp. 958-963, 2010.

[18] Y. Wu, J. Zhang, L. Dong, W. Li, J. Jia, and W. An, "Hepatic stimulator substance mitigates hepatic cell injury through suppression of the mitochondrial permeability transition," FEBS Journal, vol. 277, no. 5, pp. 1297-1309, 2010.

[19] L. L. Listenberger, D. S. Ory, and J. E. Schaffer, "Palmitateinduced apoptosis can occur through a ceramide-independent pathway," The Journal of Biological Chemistry, vol. 276, no. 18, pp. 14890-14895, 2001.

[20] L. L. Listenberger, X. Han, S. E. Lewis et al., "Triglyceride accumulation protects against fatty acid-induced lipotoxicity," Proceedings of the National Academy of Sciences of the United States of America, vol. 100, no. 6, pp. 3077-3082, 2003.

[21] S. H. Tan, G. Shui, J. Zhou et al., "Induction of autophagy by palmitic acid via protein kinase $\mathrm{C}$-mediated signaling pathway independent of mTOR (mammalian target of rapamycin)," The Journal of Biological Chemistry, vol. 287, no. 18, pp. 14364-14376, 2012.

[22] R. T. Brookheart, C. I. Michel, and J. E. Schaffer, "As a matter of fat," Cell Metabolism, vol. 10, no. 1, pp. 9-12, 2009.

[23] N. Mizushima, B. Levine, A. M. Cuervo, and D. J. Klionsky, "Autophagy fights disease through cellular self-digestion," Nature, vol. 451, no. 7182, pp. 1069-1075, 2008.

[24] B. Levine and D. J. Klionsky, "Development by self-digestion: Molecular mechanisms and biological functions of autophagy," Developmental Cell, vol. 6, no. 4, pp. 463-477, 2004.

[25] N. Cai, X. Zhao, Y. Jing et al., "Autophagy protects against palmitate-induced apoptosis in hepatocytes," Cell and Bioscience, vol. 4, article 28, 2014.

[26] S. Choi, S. Lee, Y. Lee et al., "Protective role of autophagy in palmitate-induced INS-1 $\beta$-cell death," Endocrinology, vol. 150, no. 1, pp. 126-134, 2009.

[27] C. Ebato, T. Uchida, M. Arakawa et al., "Autophagy is important in islet homeostasis and compensatory increase of beta cell mass in response to high-fat diet," Cell Metabolism, vol. 8, no. 4, pp. 325-332, 2008.

[28] S. Mei, H. Ni, S. Manley et al., "Differential roles of unsaturated and saturated fatty acids on autophagy and apoptosis in hepatocytes," Journal of Pharmacology and Experimental Therapeutics, vol. 339, no. 2, pp. 487-498, 2011.

[29] H. Koga, S. Kaushik, and A. M. Cuervo, "Altered lipid content inhibits autophagic vesicular fusion," The FASEB Journal, vol. 24, no. 8, pp. 3052-3065, 2010.

[30] C. Pecqueur, E. Couplan, F. Bouillaud, and D. Ricquier, "Genetic and physiological analysis of the role of uncoupling proteins in human energy homeostasis," Journal of Molecular Medicine, vol. 79, no. 1, pp. 48-56, 2001.

[31] Z. Xie, J. Zhang, J. Wu, B. Viollet, and M. Zou, "Upregulation of mitochondrial uncoupling protein-2 by the AMP-Activated protein kinase in endothelial cells attenuates oxidative stress in diabetes," Diabetes, vol. 57, no. 12, pp. 3222-3230, 2008.

[32] M.-J. Xu, P. Song, N. Shirwany et al., "Impaired expression of uncoupling protein 2 causes defective postischemic angiogenesis in mice deficient in AMP-activated protein kinase $\alpha$ subunits," Arteriosclerosis, Thrombosis, and Vascular Biology, vol. 31, no. 8, pp. 1757-1765, 2011.

[33] G. Baffy, "Uncoupling protein-2 and cancer," Mitochondrion, vol. 10, no. 3, pp. 243-252, 2010. 
[34] M. Jabůrek, J. Ježek, J. Zelenka, and P. Ježek, "Antioxidant activity by a synergy of redox-sensitive mitochondrial phospholipase A2 and uncoupling protein-2 in lung and spleen," The International Journal of Biochemistry \& Cell Biology, vol. 45, no. 4, pp. 816-825, 2013.

[35] L.-. Li, F. Skorpen, K. Egeberg, I. H. Jørgensen, and V. Grill, "Uncoupling protein-2 participates in cellular defense against oxidative stress in clonal $\beta$-cells," Biochemical and Biophysical Research Communications, vol. 282, no. 1, pp. 273-277, 2001.

[36] G. Mattiasson and P. G. Sullivan, "The emerging functions of UCP2 in health, disease, and therapeutics," Antioxidants and Redox Signaling, vol. 8, no. 1-2, pp. 1-38, 2006. 


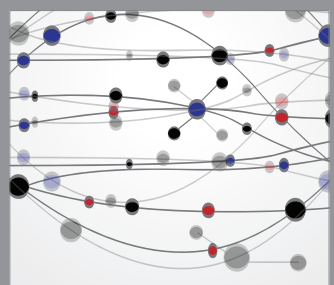

The Scientific World Journal
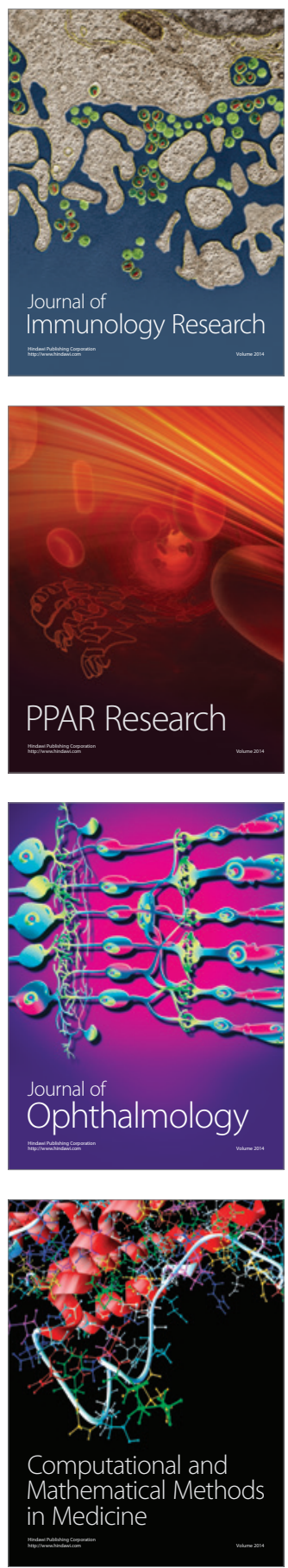

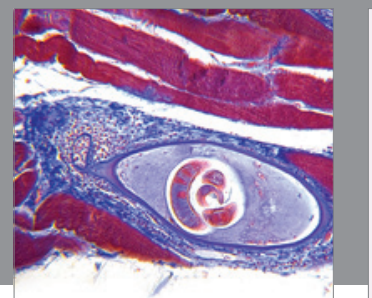

Gastroenterology

Research and Practice
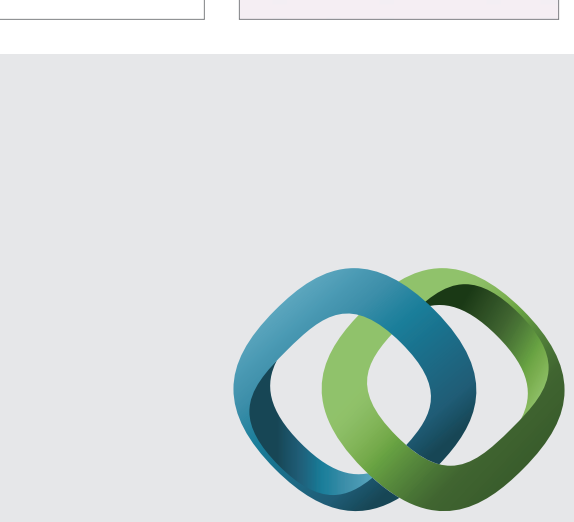

\section{Hindawi}

Submit your manuscripts at

http://www.hindawi.com
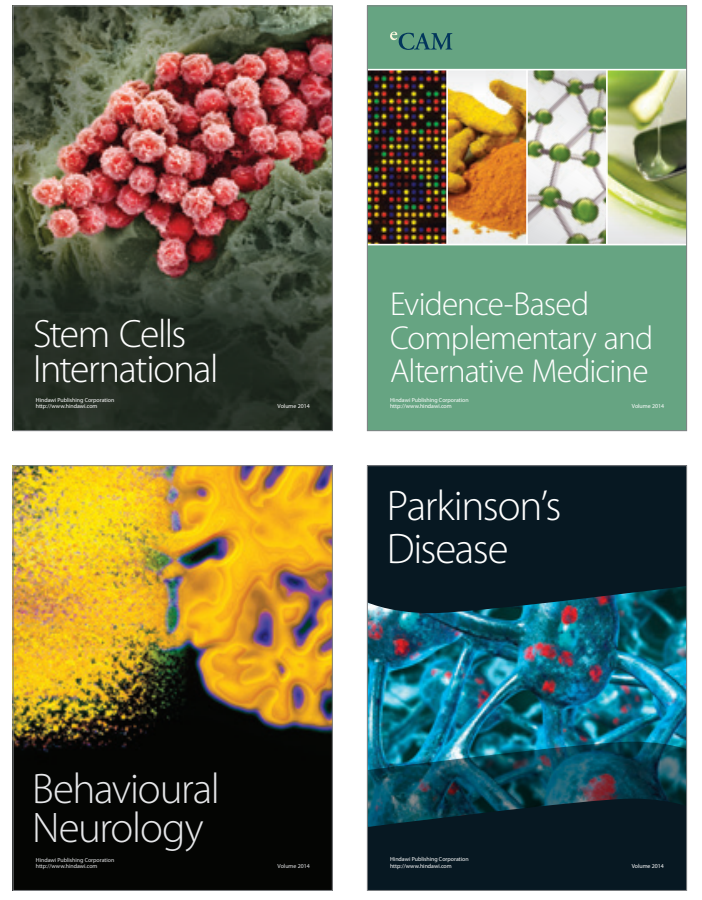
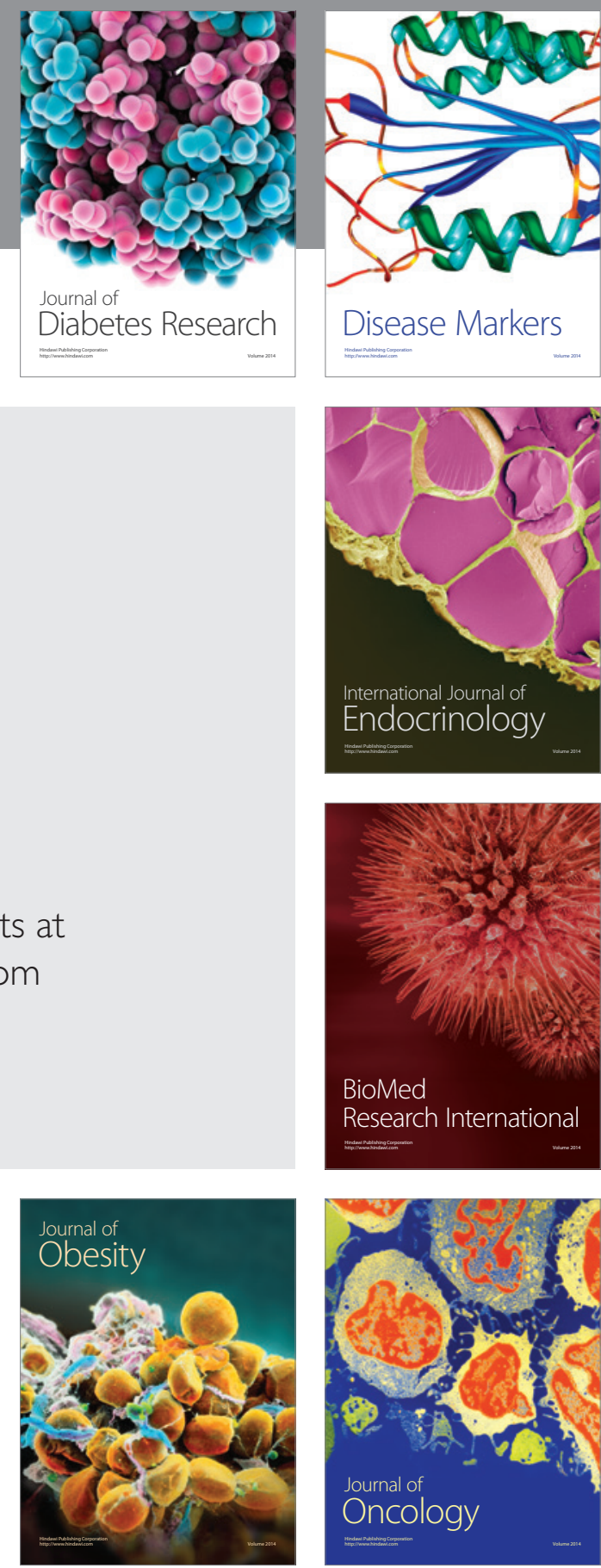

Disease Markers
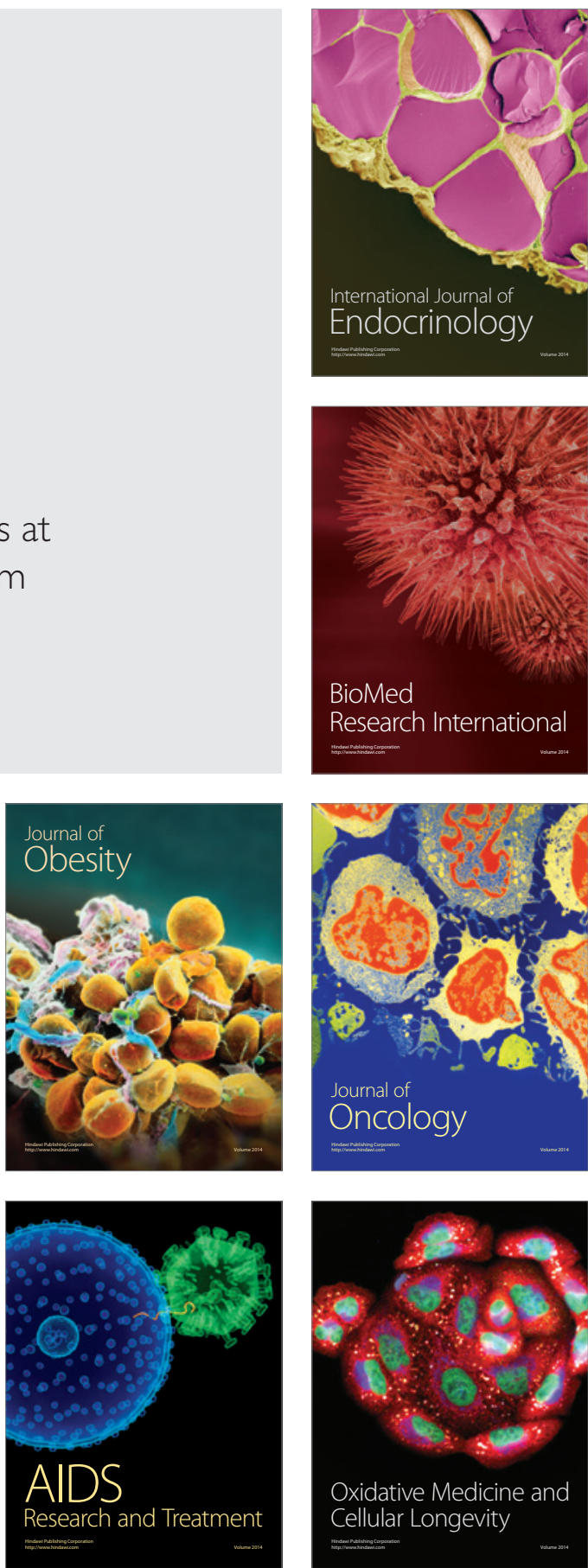